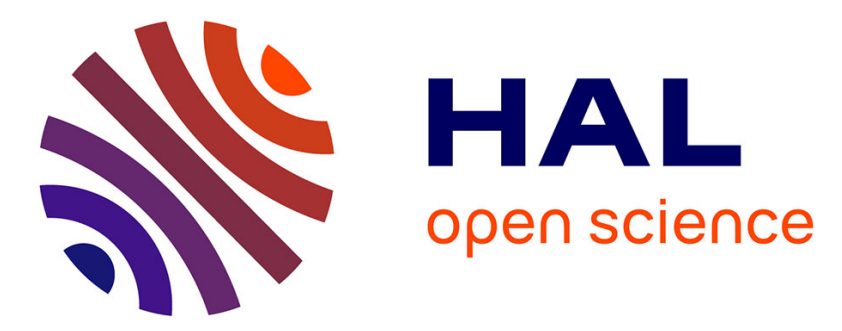

\title{
Modeling control valves in water distribution systems using a continuous state formulation
}

Olivier Piller, Jakobus Ernst van Zyl

\section{To cite this version:}

Olivier Piller, Jakobus Ernst van Zyl. Modeling control valves in water distribution systems using a continuous state formulation. Journal of Hydraulic Engineering, 2014, 140 (11), 04014052, 9 p. 10.1061/(ASCE)HY.1943-7900.0000920 . hal-01111075

\section{HAL Id: hal-01111075 \\ https://hal.science/hal-01111075}

Submitted on 29 Jan 2015

HAL is a multi-disciplinary open access archive for the deposit and dissemination of scientific research documents, whether they are published or not. The documents may come from teaching and research institutions in France or abroad, or from public or private research centers.
L'archive ouverte pluridisciplinaire HAL, est destinée au dépôt et à la diffusion de documents scientifiques de niveau recherche, publiés ou non, émanant des établissements d'enseignement et de recherche français ou étrangers, des laboratoires publics ou privés. 


\title{
Modeling Control Valves in Water Distribution Systems Using a Continuous State Formulation
}

\author{
by Olivier Piller ${ }^{1}$ and Jakobus E. van Zyl ${ }^{2}$ M.ASCE
}

\section{ABSTRACT}

Control valves are commonly used for the operation of water distribution systems. Modeling these devices typically requires that their operating states are known, or that a computationally expensive search is undertaken over all possible operating states. This paper presents a novel method of modeling control valves (including flow control, pressure sustaining, pressure reducing and check valves) in extended-period simulations of water distribution systems. Instead of the normal discrete control problem formulation, it is approached with the Karush-Kuhn-Tucker equations for an optimization problem with constraints.

The proposed method does not pre-require the operating state (open, closed, active) of each valve to be determined, as this is done implicitly. Pipe and valve flow rates and nodal heads are determined by (1) minimizing deviations from targets at control valves and (2) satisfy the state equations (conservation of mass and energy) by solving a constrained least-square problem.

\footnotetext{
${ }^{1}$ Research Scientist, Networks, water treatment and water quality Research Unit, Irstea, Bordeaux regional center, F-33612 Cestas France, email: olivier.piller@irstea.fr

2 Associate Professor, Department of Civil Engineering, University of Cape Town, South Africa, email: kobus.vanzyl@uct.ac.za
} 
21 Sensitivity equations with respect to the control variables (valve settings) are derived from

the state equations, and the control variables are updated using Levenberg-Marquardt iterations. The results of simple problems and case studies are presented to demonstrate the effectiveness of the approach.

Keywords: Water distribution systems; Hydraulic models; Control valves; Algorithms; Least-squares optimization; Penalty method; Flow control; Pressure control

\section{INTRODUCTION}

Water distribution systems have to provide a high level of service under widely varying conditions. To achieve this, engineers often employ control valves to manage flows and pressures. Control valves can operate mechanically (such as check valves) or through hydraulic circuits (such as flow control and pressure regulating valves), and can be controlled by local conditions or an external signal.

The common algorithms used for modeling the hydraulics of a water distribution system do not model the time-varying behavior of the system continuously, but calculate ónapshotsôof the systemôs hydraulic state at certain points in the simulation period. At each time step, the snapshot solver has to solve the hydraulic network equations while simultaneously calculating the settings of all the control valves in the system. Tank levels are updated between snapshot simulations using a simple Euler integration scheme.

The commonly used open source software, Epanet (Rossman, 2000), uses a set of control rules to calculate control valve settings. Although the Epanet method works well in practice and is widely accepted in the hydraulic modeling community, there is no guarantee that its heuristic algorithm will be able to find the correct control valve settings in all cases. In fact, 
Simpson (1999) illustrated this through a number of control valve problems for which the Epanet hydraulic engine could not find a solution, or produced incorrect results.

Alternative methods for modeling control valves have developed in recent years. Piller and Bremond (2001) proposed a least-squares global optimization approach to determine the control valve state by minimizing the differences between the target settings and calculated values. Piller et al. (2005) applied the same optimization framework with an attempt to model time-varying behavior of the system continuously using slow transients (or rigid column without water hammer). This allowed them to model the continuous changes in the system state until an equilibrium (steady) state is achieved. The reaction speed of the control valve can be incorporated in the calculations by adding a constraint in the optimization solver. The authors noted that certain solutions that are infeasible using a demand-driven approach are in fact possible in real life, and can be solved correctly if a pressure-driven approach is followed.

Deuerlein et al. (2005) proposed a method based on Nash Equilibrium to determine the correct settings of pressure control valves. The valve head losses were taken as optimization variables and were estimated with a gradient-based algorithm that minimizes the corresponding convex variational problem. This method simultaneously solves as many constrained convex minimization problems as the number of pressure regulating valves plus one. The derived system is composed of the steady state equations (reduced to the loop energy balances) with one additional equation for each pressure regulating valve and complementary slackness condition. This system employs nonnegative Lagrange multipliers and its Jacobian is non-symmetrical, which may lead to a reduced solving efficiency. This reflects the fact that the system is not derived from a single optimization problem. It is worth 
noting that the authors found their method to be robust and to produce good results based on several example problems. In a further paper, Deuerlein et al. (2008) used the same approach, but with the residual squared between the predicted value and the target value. This represents a more direct objective function similar to that used by Piller and Bremond (2001). Moreover, the authors described some simple examples for which no solutions or no unique solutions could be found.

Another method to handle flow control and check valves was proposed by Deuerlein et al. (2009). They use the content and co-content theory to define conditions that guarantee the existence and uniqueness of the solution before simultaneously solving the network hydraulics and valve settings. Subdifferential analysis is used to deal with the nondifferentiable flow versus headloss relationships of flow control and check valves, and the combined equations are solved as a constrained nonlinear programming problem. An interesting result was the interpretation of the flow rate inequality multiplier as the head loss over the flow control valve.

In this study, different approaches are used to solve flow and pressure control valves in a hydraulic network. Flow control valves are handled by applying an external penalty function to the valveôs headloss equation in the vicinity of the valve setting. Check valves are handled as special flow control valves with a minimum flow rate setting of zero. The flow control valves are then solved with the other network hydraulic equations using a standard network solver. Pressure control valves are solved externally to the hydraulic solver by employing a Newton Projection Minimization algorithm, for which global convergence is guaranteed. 
An overview of the snapshot hydraulic equations is presented before describing the proposed algorithms for handling flow and pressure control valves. The proposed method is illustrated on a number of example problems for which Epanet is not currently able to find correct solutions.

\section{HYDRAULIC MODEL}

Hydraulic equations. Equations describing the hydraulics of water distribution systems are based on the principles of conservation of mass and energy for an incompressible fluid. These equations are solved to obtain the unknown flow rates in pipes, and hydraulic heads at nodes. The hydraulic network equations are described by:

$$
\left\{\begin{aligned}
\mathbf{A Q}^{*}+\mathbf{d} & =\mathbf{0}_{n u} \\
\mathbf{h}^{*}-\mathbf{A}^{\top} \mathbf{H}^{*}-\mathbf{A}_{f}{ }^{\top} \mathbf{H}_{f} & =\mathbf{0}_{n p} \\
\mathbf{h}^{*} & =\mathbf{h}\left(\mathbf{Q}^{*}, \mathbf{r}\right)
\end{aligned}\right.
$$

\section{Code de champ modifié}

Mis en forme : Police :12 pt, Ne pas vérifier l'orthographe ou la grammaire

Where $\mathbf{Q}^{*}$ is the vector of link flowrates with size $n p$ (number of links), $\mathbf{d}$ the vector of nodal demands with size $n u$ (number of unknown-head nodes), $\mathbf{A}$ an $n u \times n p$ incidence matrix representing unknown-head node connectivity, $\mathbf{A}_{\mathrm{f}}$ an $n f$ (number of fixed-head nodes) x $n p$ incidence matrix of fixed-head nodes, $\mathbf{H}^{*}$ the vector of hydraulic heads for the unknown-head nodes, $\mathbf{H}_{\mathrm{f}}$ the vector of hydraulic heads for the fixed-head nodes, $\mathbf{h}^{*}$ is a vector of link head losses. $A_{i j}=+1$ if the pipe $j$ leaves node $i$ and $i$ is an unknown head node; $A_{i j}=-1$ if it enters node $\mathrm{i}$ and $\mathrm{i}$ is an unknown head node; and $\mathrm{A}_{\mathrm{ij}}=0$ otherwise. The same definition applies to $A_{f}$ but with i a fixed head node. The first two equations describe the conservation of mass and energy respectively, and are linear. The last is a nonlinear equation that describes the relationship between the link flow rates and head losses, typically based on the DarcyWeisbach or still Hazen-Williams formulae. 
Solving the hydraulic equations. Various methods have been proposed for solving water distribution system hydraulics. The first Loop method proposed by Cross (1936) updates the value of loop flow rates for the corresponding loop energy equation subject while fixing all other flow rates (a similar Node method was also proposed by Cross). It can be shown (Piller, 1995) that the Hardy Cross Loop method corresponds to a cyclic relaxation for the minimization of an energy function. The convergence of the latter can be drastically improved by simultaneously considering all the loops and nodes.

Subsequently, several Newton-Raphson based algorithms have been proposed. These algorithms may be classified as:

- Nodal methods, which are based on the nodal mass balances and describe the system state with head variables, e.g. (Chandrashekar and Stewart 1975; Lam and Wolla 1972; Martin and Peters 1963).

- Loop or simultaneous path methods, which are based on loop energy balances and describe the system state with loop flow rate variables, e.g. (Carpentier et al., 1985; Epp and Fowler 1970).

- The Linear method proposed by Wood and Charles (1972), which is based on mass and energy balances and describes the system with link flow rate variables.

- Hybrid methods, which are based on mass and energy balances and describe the system with both link flow rates and nodal head variables, e.g. (Carpentier et al., 1985; Todini and Pilati, 1988; Piller 1995).

140 The Loop, Linear and Hybrid method classes result in equations that are the best conditioned

141 for fast convergence (they converge in the same number of iterations from the same starting 
point), but the Hybrid method generally has fewer computational overheads than the other

two methods, and is thus preferred. The Global Gradient Algorithm method by Todini and Pilati (1988) was implemented in the public domain Epanet software (Rossman 2000), which has become the standard method used in research and industry. Alternative Hybrid formulations are employed in software packages such as Piccolo (2013) and Porteau (2013). A problem with the Newton-Raphson based algorithms is that the global convergence of the method is only guaranteed if the initial solution is sufficiently close to the final solution (see e.g. the global damped Newton theorem in Ortega and Rheinboldt; 1970).

For global convergence to be guaranteed, it is necessary to adopt an optimization approach. Such formulations were proposed by Collins et al. (1978), Carpentier et al. (1985) and Piller (1995). An optimization approach allows correction made to the solution at each iteration to be tested for effectiveness, thus allowing numerical instabilities to be avoided. In addition, the existence and uniqueness of a solution to the equations can be proven, and thus convergence on a unique solution is guaranteed.

The proposed hydraulic solver is derived from the Content formulation by Collins, which describes the principle of least action for the hydraulic network, and can be written as:

$$
\begin{aligned}
& \min _{\mathbf{Q}} f(\mathbf{Q})=\mathbf{Q}^{T} \overline{\mathbf{h}}(\mathbf{Q})-\mathbf{Q}^{T} \mathbf{A}_{f}{ }^{\top} \mathbf{H}_{f} \\
& \text { subject to }-\mathbf{A Q} \mathbf{Q}-\mathbf{d}=\mathbf{0}_{\text {пи }}
\end{aligned}
$$
vérifier l'orthographe ou la grammaire

Where $f(\mathbf{Q})$ is called the Content function of the system. The units of the Content function are that of power per unit weight. It is expressed as the sum of two terms with the first term representing the power dissipated in the network to reach the final steady state and the second the external power available to the system. $\mathbf{Q}$ is a vector of the link flowrates that complies 
with the conservation of mass, but not necessarily with the conservation of energy (i.e. the link flowrates in the solver before convergence has been achieved). $\overline{\mathbf{h}}$ is the vector of average headlosses between flowrates of zero to $\mathbf{Q}$ and its $\mathrm{i}^{\text {th }}$ component is:

$$
\overline{h_{i}}\left(Q_{i}\right)=\left(1 / Q_{i}\right) \int_{0}^{Q_{i}} h_{i}(u), \mathrm{Q}_{i} \neq 0 \text { and } \overline{h_{i}}(0)=0
$$

$\mathbf{Q}^{*}$ is used for the correct values of the flowrates after convergence (that complies with both mass and energy balance). Thus $f(\mathbf{Q})$ is at a minimum when $\mathbf{Q}=\mathbf{Q}^{*}$.

Moreover, the headloss vector function $\mathbf{h}$ is modified near zero to ensure that $f(\mathbf{Q})$ is strongly convex and twice continuously differentiable. The modification is required to ensure that the first derivative of the headloss function does not become zero at a flowrate of zero $\ddot{i}$ for details, see Piller (1995). This smoothing process is not necessary to guarantee the existence and uniqueness of the solution, but avoids numerical problems experienced by hydraulic solvers when flows in pipes are close to zero (all solver algorithms have to deal with this problem in some way).

The Content model minimization problem (2) is solved with a Lagrange-Newton method that is obtained by applying a Newton method to find a saddle point of the problem Lagrangian. At each iteration, updated heads and flowrates, as well as the Content function are calculated. If the descent criterion (similar to the Wolfe conditions) is not satisfied (i.e. the Content function does not decrease sufficiently), the flowrate adjustment is diminished by a factor $\rho_{\mathrm{k}}$ to ensure that global minimum of the Content function is found. At each iteration, the updated heads and flowrates are calculated by: 


$$
\begin{aligned}
& \mathbf{H}^{k+1}=\left(\mathbf{A D}_{k}^{-1} \mathbf{A}^{T}\right)^{-1}\left[\mathbf{A} \mathbf{D}_{k}{ }^{-1}\left\{\mathbf{h}\left(\mathbf{Q}^{k}\right)-\mathbf{A}_{f}{ }^{T} \mathbf{H}_{f}\right\}-\left\{\mathbf{A} \mathbf{Q}^{k}+\mathbf{d}\right\}\right] \\
& \mathbf{Q}^{k+1}=\mathbf{Q}^{k}-\rho_{k} \mathbf{D}_{k}^{-1}\left[\mathbf{h}\left(\mathbf{Q}^{k}\right)-\mathbf{A}_{f}^{T} \mathbf{H}_{f}-\mathbf{A}^{T} \mathbf{H}^{k+1}\right]
\end{aligned}
$$

with $\mathbf{D}_{k}=\mathbf{D}\left(\mathbf{Q}^{k}\right)=\partial_{Q} \mathbf{h}\left(\mathbf{Q}^{k}\right)$ the Jacobian matrix of $\mathbf{h}$ in $\mathbf{Q}^{k}$ and $\mathbf{A} \mathbf{D}_{k}^{-1} \mathbf{A}^{T}$ is a symmetric,

A convergence criterion on the energy balance on the pipes is used by stopping when $\max _{i}\left\{\left(\mathbf{h}\left(\mathbf{Q}^{k}\right)-\mathbf{A}_{f}{ }^{T} \mathbf{H}_{f}-\mathbf{A}^{T} \mathbf{H}^{k+1}\right)_{i}, \mathrm{i}=1, \cdots, \mathrm{n}_{p}\right\} \leq \varepsilon$, with Ůa small value.

\section{PROPOSED MODEL FOR FLOW AND PRESSURE REGULATING DEVICES}

195 In this study, the optimization approach used in the hydraulic solver was expanded to handle control valves. Different approaches are used for the modeling of flow and pressure control valves. The headloss function of a flow control valve is adjusted by adding a penalty when the valve setting is violated. This modified headloss function is then treated like any other link in the hydraulic solver. Check valves are handled as special flow control valves with a minimum flow rate setting of zero. Pressure control valves are solved externally to the hydraulic solver by employing a Newton Projection Minimization algorithm, for which global convergence is guaranteed. The target flowrates and heads are subjected to constraints in the form of the conservation laws and the hydraulic behavior of elements in the system.

Flow regulating valves include flow control valves that prevent the flow rate through the 
since this results in a simpler model and avoids numerical problems in valves with very small

head losses.

212 In the proposed approach, the problem is not solved with hard inequality constraints (like in

213 Deuerlein et al., 2009) but by adding penalties to the Content function. This exterior penalty method facilitates the satisfaction of constraints while being robust and simple to implement. The hydraulic solver used is based on an optimization approach, and this facilitates the simultaneous handling of system links and flow control valves. The modified Content optimization problem (2) now becomes:

$$
\begin{aligned}
& \min _{\mathbf{Q}} \tilde{f}(\mathbf{Q}, \mathbf{r})=f(\mathbf{Q})+\frac{1}{3} \sum_{j \in J_{F C V}} r_{j} \max \left(0, Q_{j}-Q_{j}^{\text {set }}\right)^{3} \\
& \text { subject to - } \mathbf{A Q}-\mathbf{d}=0_{n u}
\end{aligned}
$$

Where $J_{F V C}$ is the index set of pipes with a flow control valve; the $r_{\mathrm{j}}$ are positive resistance coefficients; and the last term penalizes violations of flow control valve settings. In general the penalty function method requires that $\tilde{f}\left(\mathbf{Q}, \mathbf{r}^{k}\right)$ is minimized for a sequence of $\mathbf{r}^{\mathrm{k}}$ until a suitable solution is found. However, for this application it was found good results are obtained with a large identical scalar $r_{\max }$ value. The corresponding headloss penalty is obtained as:

$$
h_{j}^{F C V}\left(Q_{j}, r_{\max }\right)=r_{\max } \max \left(0, Q_{j}-Q_{j}^{s e t}\right)^{2}=h_{0} \max \left(0, \frac{Q_{j}-Q_{j}^{s e t}}{\Delta Q}\right)^{2}
$$

226 With $h_{0}$ the headloss penalty for a flow rate violation of $\Delta Q ; Q_{j}$ is the flowrate in the pipe j; $Q_{j}^{s e t}$ is the setting value; and $\mathbf{h}^{\mathrm{FCV}}$, the headloss penalty function of $\mathbf{Q}$, is the gradient of the additional term to the Content function. 


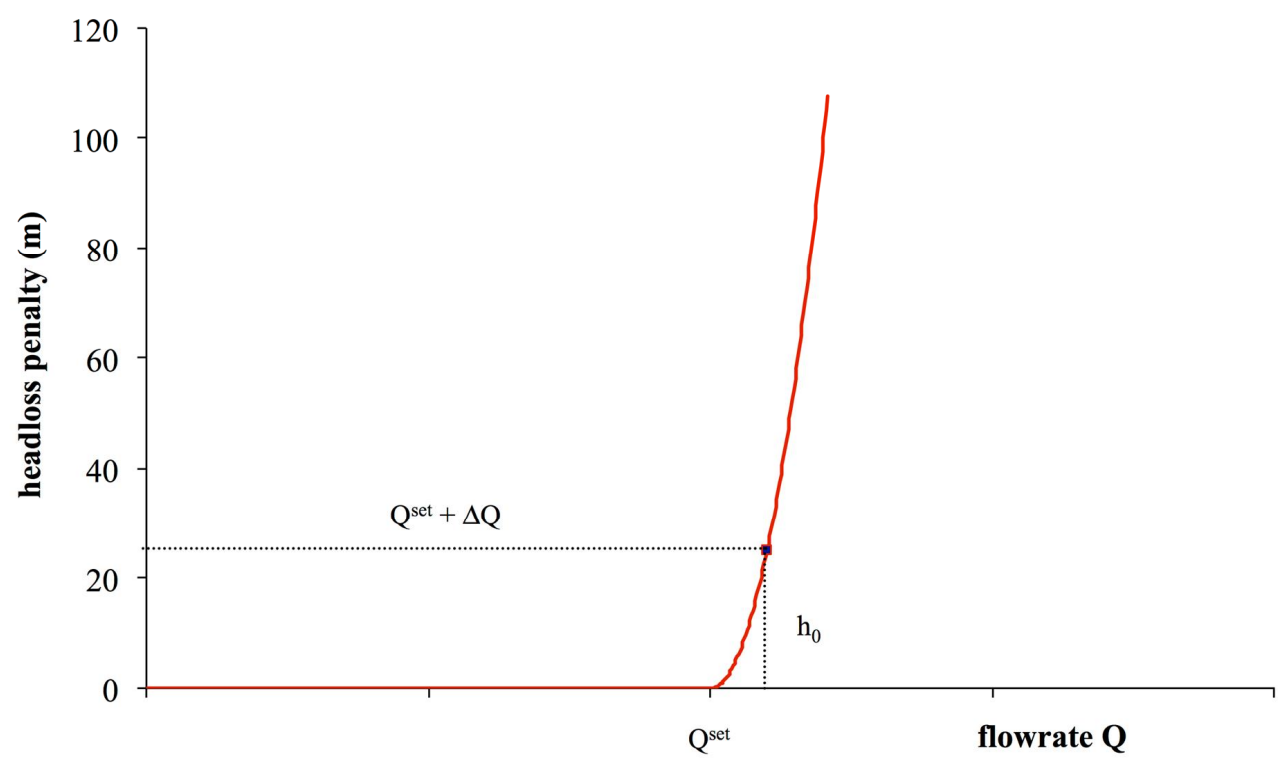

233 Figure 1. Headloss modeling of a flow control valve by external penalty.

234 Check valves can be modeled by considering them as a special type of flow control valve

235 with the constraint that $Q_{k} \geq 0$. The penalty function for check valve is described by:

$$
h_{k}^{C V}\left(Q_{k}, r_{\max }\right)=-r_{\max } \max \left(0,-Q_{k}\right)^{2}=-h_{0} \max \left(0, \frac{-Q_{k}}{\Delta Q}\right)^{2}
$$




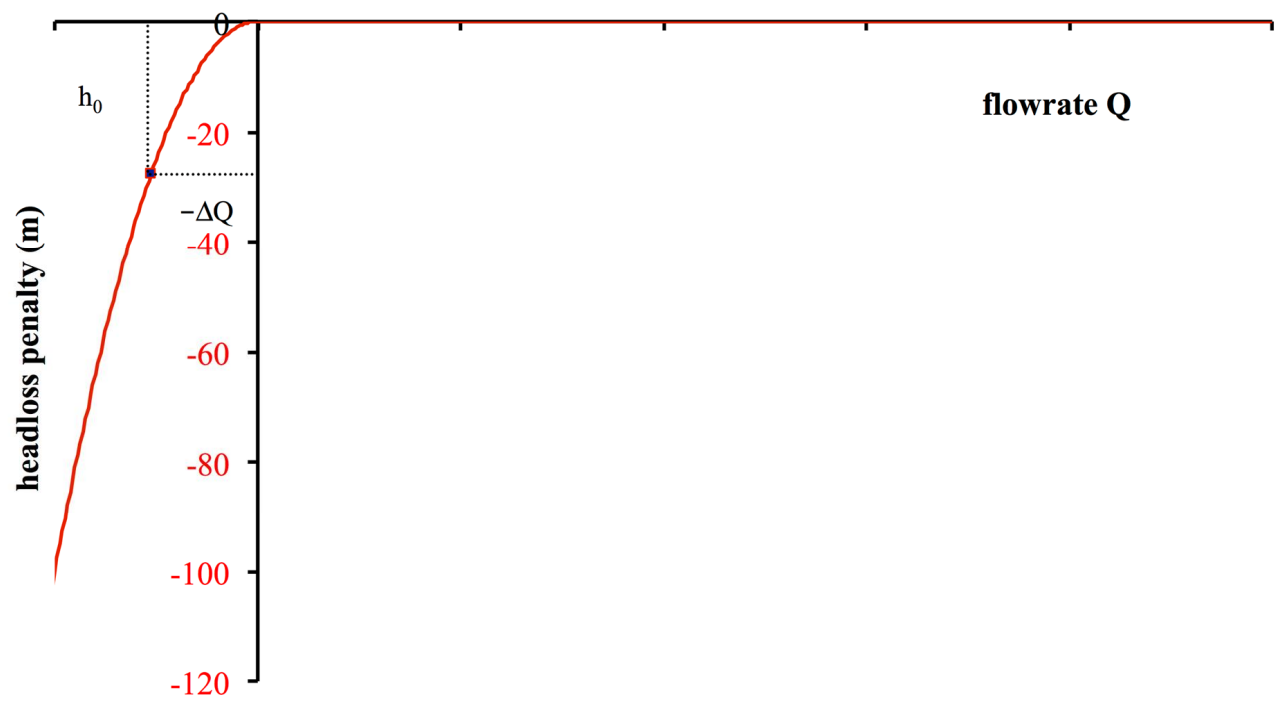

239 Figure 2. Headloss modeling of a check valve by external penalty.

240 The generalized Content minimization problem for handling FCVs and CVs is then:

$$
\begin{aligned}
& \min _{\mathbf{Q}} \tilde{f}(\mathbf{Q}, \mathbf{r})=f(\mathbf{Q})+\frac{1}{3} r_{\max }\left[\sum_{j \in J_{F C V}} \max \left(0, Q_{j}-Q_{j}^{s e t}\right)^{3}+\sum_{k \in K_{C V}} \max \left(0,-Q_{k}\right)^{3}\right] \\
& \text { subject to - } \mathbf{A Q}-\mathbf{d}=0_{n u}
\end{aligned}
$$

Code de champ modifié

Mis en forme : Police : $12 \mathrm{pt}$, Ne pas vérifier l'orthographe ou la grammaire

\section{Pressure Regulating Devices (PRDs)}

\section{Formulation}

245 A pressure-reducing valve (PRV) aims to maintain a certain maximum pressure on the downstream side of the valve. PRVs are often used at the supply points of pressure zones to ensure that pipes are not overloaded and leakage is minimized. On the other hand, a pressuresustaining valve (PSV) is used to maintain a minimum pressure on the upstream side of the valve. 
251 Piller and Van Zyl (2009) used dummy pressure sustaining valves as a modeling trick to correct hydraulic predictions for network section supplied via a high-lying node experiencing negative pressure. This may occur if the normal supply pipe to the network section has failed. In practice, air will enter the system at the elevated node (e.g. through air valves, leaks or open taps), and thus the supply to the network section will likely be interrupted.

Just like flow control valves, pressure regulating devices (PRDs) are modeled as part of existing links with a given target pressure on the downstream $\left(i_{D}\right)$ or upstream $\left(i_{U}\right)$ PRD sides.

Thus for a PRV:

$$
H_{i_{D}} \leq H_{i_{D}}^{\text {set }}
$$

and for a PSV:

$$
H_{i_{U}} \geq H_{i_{U}}^{\text {set }}
$$

If $\mathbf{S}$ is the selection matrix of the $n t$ nodes with pressure setting targets, the complete set of constraints can be written in matrix form as:

When in use, PRVs and PSVs create local headlosses to get the network pressures as close as possible to the head set point vector $\mathrm{H}^{\text {set }}$ (target pressure + ground level). These local headlosses are added to the total headlosses $\mathbf{h}(\mathbf{Q})$ for links with such devices:

$$
\mathbf{h}^{P R D}(\mathbf{Q}, \mathbf{r})=\mathbf{B}(\mathbf{Q}) \mathbf{r} \text { with } \mathbf{B}(\mathbf{Q})=\mathbf{C S}_{\mathbf{Q}}{ }^{T}, r_{i}=\frac{8 K_{i}}{g \pi^{2} D_{i}^{4}}, i=1, \cdots, n t
$$



matrix of element $C_{i i}=\max \left(0, Q_{i}\right)^{2}$ and $\mathbf{S}_{\mathrm{Q}}$ is the matrix of size nt $\mathrm{x} \mathrm{np}$ for identifying the pipes with PRVs. Control valves only act in one direction - depending on how they are defined, these valves will either stop flow reversal, or, if negative flow is allowed, behave as pipes with known secondary headloss coefficients.

Pressure regulating devices are handled with a function that penalizes deviations from the target settings, as described by the first term in this function:

$$
\begin{aligned}
& \min _{\mathbf{r}} c(\mathbf{r})=\frac{1}{2}\left(\mathbf{S H}(\mathbf{r})-\mathbf{H}^{\text {set }}\right)^{T} \mathbf{I}^{+}\left(\mathbf{S H}(\mathbf{r})-\mathbf{H}^{\text {set }}\right)+\frac{1}{2} m\left(\mathbf{r}-\mathbf{r}_{0}\right)^{T} \mathbf{I}^{+}\left(\mathbf{r}-\mathbf{r}_{0}\right) \\
& \text { subject to: } \mathbf{0}_{n t} \leq \mathbf{r} \leq r_{\max } \mathbf{1}_{n t}
\end{aligned}
$$

The second term in the equation is a Tikhonov regularization term used to ensure that numerical problems are avoided in converging to a unique solution. The value of $r_{\max }$ is the same as that used for flow control valves: $r_{\max }=h_{0} / \Delta Q^{2}$ in Figs. 1 and $2 . \mathbf{I}^{+}$is the indicator matrix to implement the pressure control valve behavior for positive flowrates only, $\mathbf{r}_{0}$ is the value of $\mathbf{r}$ from the previous iteration (or an initial estimate), and $m$ is the Tikhonov factor used to control the convexity of the function. The Tikhonov regularization term is only included when the function has insufficient convexity, and in our experience it is mostly equal to zero.

The function $c$ is not differentiable at $r_{\mathrm{i}}$ such as $Q_{\mathrm{i}}\left(r_{\mathrm{i}}\right)=0$. However, since control valves are active in a very small positive range of $Q_{\mathrm{i}}$, and is either open or closed outside this range, it wasnâ necessary to modify the $\mathbf{I}^{+}$term. 
According to the Weierstrass theorem, there exists a solution for the problem by continuity of $c$ on a non-empty compact (closed and bounded) constraint set. Because of a suitable $m$ coefficient, the strict convexity of $c$ guarantees the uniqueness of the solution.

For different pressure settings of a single PRV, Figure 3Figure 3 illustrates general form, in relation to the $K$ (dimensionless) coefficients, of the sum of squares of the residuals that are obtained:

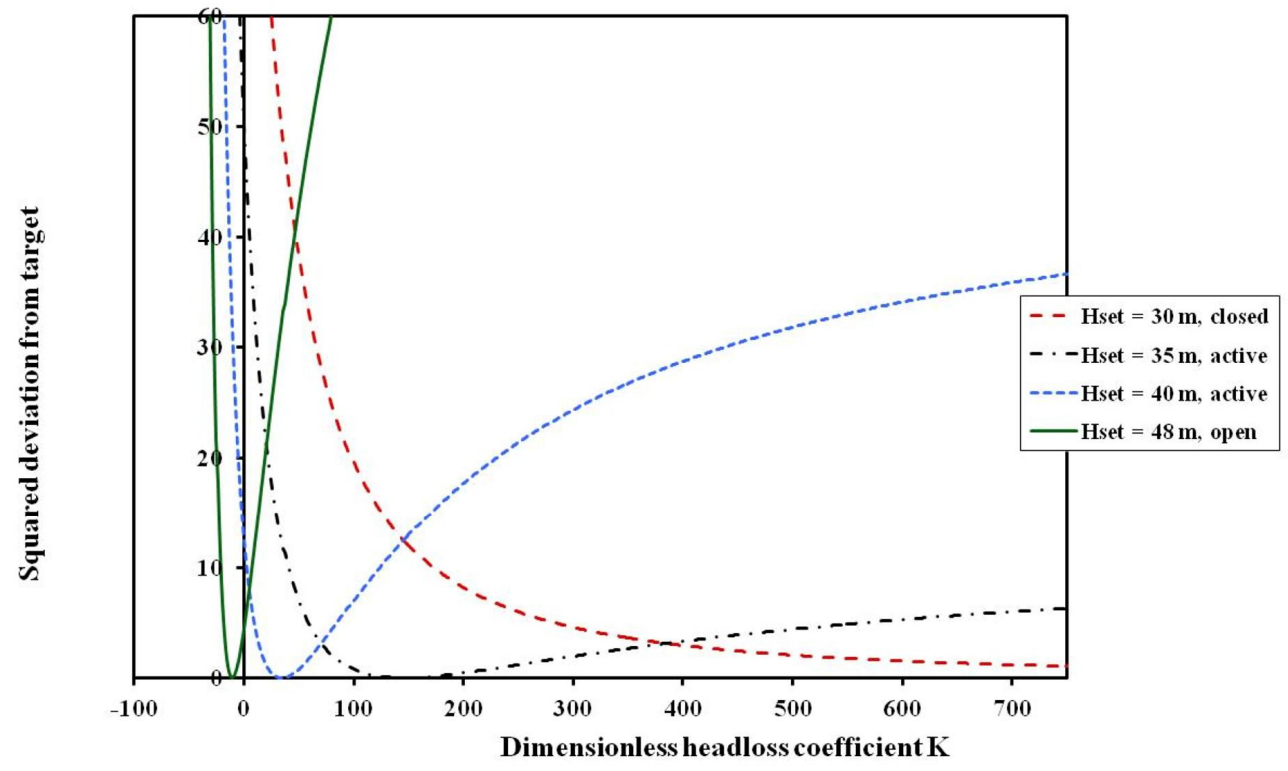

Figure 33. General form of criterion $\mathrm{c}(X)$ to be minimized with $\mathrm{m}$ taken at zero.

For the four curves shown, the objective function $\mathrm{c}$ has a horizontal asymptote and a finite limit when $K$ tends to infinity. There is a head setting $H^{\text {set }}$, below which the objective c does not have a minimum, in Figure 3Figure 3 when $H^{\text {set }}$ Ò $30 \mathrm{~m}$. In such cases, the solution of (8) is $K_{\max }$ if $m=0$ and correspondingly the valve status is álosedô For intermediary head Mis en forme : Anglais (États Unis) Code de champ modifié Mis en forme : Anglais (États Unis) Mis en forme : Anglais (États Unis) Mis en forme : Anglais (États Unis) 
greater than or equal to $45 \mathrm{~m}$, the valve status is @́penô and the unconstrained minimum

occurs in the second (negative) quadrant. The solution of (8) for an open valve is $K=0$. Note

that the four curves are smooth, they each have no more than one minimum in the feasible points.

With the convexity and the differentiability of the least-squares criterion $c$, it is possible to and Tucker (KKT) equations (a generalization of Lagrange condition for inequality constraints). These optimality conditions are useful to determine the correct status of the valves (rather than the valve settings). Once correct statuses of the PRD valves are determined, a second-stage least-squares problem Eq. (8) should be formulated with only the deviations from the target settings for PRDs that are active to determine the exact local head losses created by the control valves in order to meet the pressure targets.

To solve the KKT equations, the gradient of $c$ has to be determined. Using the implicit function theorem, we can show that $\mathbf{y}=\mathbf{H}(\mathbf{r})$ is a continuous differentiable function with regards to the $\mathbf{r}$ variables. This gives an expression for the gradient of $c$ :

$$
\nabla c(\mathbf{r})=\mathbf{J}^{T}\left(\mathbf{S H}(\mathbf{r})-\mathbf{H}^{s e t}\right)+m\left(\mathbf{r}-\mathbf{r}_{0}\right)
$$

$$
\mathbf{J}=\mathbf{S} \partial_{\mathbf{r}} \mathbf{H}=\mathbf{S}\left(\mathbf{A} \mathbf{D}^{-1} \mathbf{A}^{T}\right)^{-1} \mathbf{A} \mathbf{D}^{-1} \mathbf{B}
$$


331 is the Jacobian matrix of the $\mathbf{H}$ function at PRD target nodes with respect to the $\mathbf{r}$ 332 coefficients, $\mathbf{B}$ is the same as in Eq. (7) and $\mathbf{D}$ is the derivative of $\mathbf{h}$ with respect to the flow 333 rate $\mathbf{Q}$. The total headloss function $\mathbf{h}(\mathbf{Q}, \mathbf{r})$ includes friction losses, FCVs, CVs and PRDs. 334 The calculation of the gradient of $\mathrm{c}$ is immediate, as the matrix to be inverted is very sparse 335 and its Cholesky decomposition is known from the current hydraulic solution of system (Eq. 1) with the previous values of $\mathbf{r}$.

Since $c$ is continuously differentiable, and the constraints are linear, the first order KKT optimality conditions are met (e.g., see Bazaraa, 1993). Therefore there exist two positive multiplier vectors $\mathbf{M}^{1}$ and $\mathbf{M}^{2}$ Ó $\mathbf{0}_{\mathrm{nt}}$ such that:

$$
\nabla c(\check{\mathbf{E}})=\mathbf{M}^{1}-\mathbf{M}^{2}
$$

This consists of the Dual Feasibility conditions while

$$
\left(\mathbf{M}^{1}\right)^{T} \breve{\mathbf{E}}=0 \text { and }\left(\mathbf{M}^{2}\right)^{T}\left(\check{\mathbf{E}}-r_{\max } \mathbf{1}_{n t}\right)=0
$$

are the Complementary Slackness conditions with being the optimal solution. The dual feasibility condition states that the gradient is no longer sign-constrained.

These two conditions are used to check whether the KKT conditions have been met, i.e. whether the correct solution for valve status has been found.

If $r_{i}=0$ (the $i^{\text {th }}$ pressure control valve status is open), then by (11) it is necessary that $M_{i}^{2}=0$ and Eq. (10) indicates that the $i^{\text {th }}$ component of the gradient must be positive or zero. In identical manner, if $\mathrm{r}_{\mathrm{i}}=\mathrm{r}_{\max }$ (the $\mathrm{i}^{\text {th }}$ pressure control valve status is closed), then $M_{i}^{1}=0$ and the corresponding gradient component must be negative or zero. Finally, if $0<r_{i}<r_{\max }$ (the $i^{\text {th }}$ 
pressure control valve is active), then necessarily $M_{i}^{1}=M_{i}^{2}=0$ and the $i^{\text {th }}$ gradient component should be zero.

\section{Projected Levenberg-Marquardt Solution Algorithm}

The solution method used is a slight modification of the Levenberg-Marquardt (LM) algorithm that accounts for all the constraints.

At the start of the solution algorithm, initial control valve statuses are obtained from the previous solution or initial settings. The system hydraulics is then solved, and the control valve $\mathbf{r}$ resistances estimated with the iterative formula:

$$
\mathbf{r}^{i+1}=\mathbf{r}^{i}-\mathbf{P}_{i}\left[\mathbf{J}_{i}^{T} \mathbf{J}_{i}+m \mathbf{u}_{n t}+e_{i} \operatorname{diag}\left(\mathbf{J}_{i}^{T} \mathbf{J}_{i}\right)\right]^{-1} \nabla c^{i}
$$

Where $e_{i}$ is the $L M$ damping factor, $P_{i}$ is the projection matrix for bounded primary constraints in (8) (i.e. valves that have fixed álosedô or ópenôstatuses). The value of $\mathrm{e}_{\mathrm{i}}$ is increased if the primal feasibility conditions (PF) are not complied with, if $\mathbf{J}_{\mathrm{i}}^{\mathrm{T}} \mathbf{J}_{\mathrm{i}}$ is an illconditioned matrix or if there is no descent. In each step $i$, the hydraulic system is solved to determine $\mathbf{Q}\left(\mathbf{r}^{\mathrm{i}}\right)$ and $\mathbf{H}\left(\mathbf{r}^{\mathrm{i}}\right)$. The operation of the pressure regulating devices is modeled by adjusting the local head loss coefficients to satisfy the optimality of a least squares problem.

The algorithm (Eq. (12)), which is a projected method on the box constraints of Eq. (8), will not change valves with status ópenô or álosedôduring iterations. A valve that is initially áctiveômay becomes ópenôif $\mathrm{K}_{\mathrm{i}}$ Ò1E-3 and álosedôif $\mathrm{r}_{\mathrm{i}}$ Ó $\mathrm{r}_{\max } \ddot{\mathrm{I}} 1 \mathrm{E}-3 * \mathrm{r}_{\max }$.

The KKT conditions (Eqs. (10) and (11)) are checked after the iterative scheme Eq. (12) has converged. If all the Lagrange multipliers are non-negative, the KKT conditions are satisfied 
and the first-step optimization of (8) can be terminated. If the KKT optimality conditions are not met, the pressure control valve with the most negative KKT multiplier is released, i.e. its status is changed from ónon-activeô(either ópenôor âlosedô) to áctiveô

Once the statuses of the PRD valves have been determined, a second-stage least-squares problem (Eq. (8)) is solved with the same constraints, but with deviations from the target settings only for áctiveôPRDs in the objective function: this is done to determine the exact local head losses created by active control valves in order to meet the pressure targets. This second-stage of the solution has to be done to remove any biases that fully open or closed valves have introduced in the solution.

\section{VALIDATION TESTS}

The proposed method was applied to a number of example networks:

- A simple network with a pressure-reducing valve on a pipeline between two tanks. This example was provided to illustrate the good convergence of the method when there is no interaction between valves.

- A simple network consisting of a flow control valve and a pressure-reducing valve in series on a pipeline between two tanks. This network posed a problem for early versions of Epanet. - A simple network consisting of pressure-sustaining and pressure-reducing valves in series. This network poses a problem for the current version of Epanet.

- A simple network consisting of two valves in parallel that strongly interacts with each other.

The simulations results are discussed with an emphasis on the convergence characteristics of the method. 

(1999).

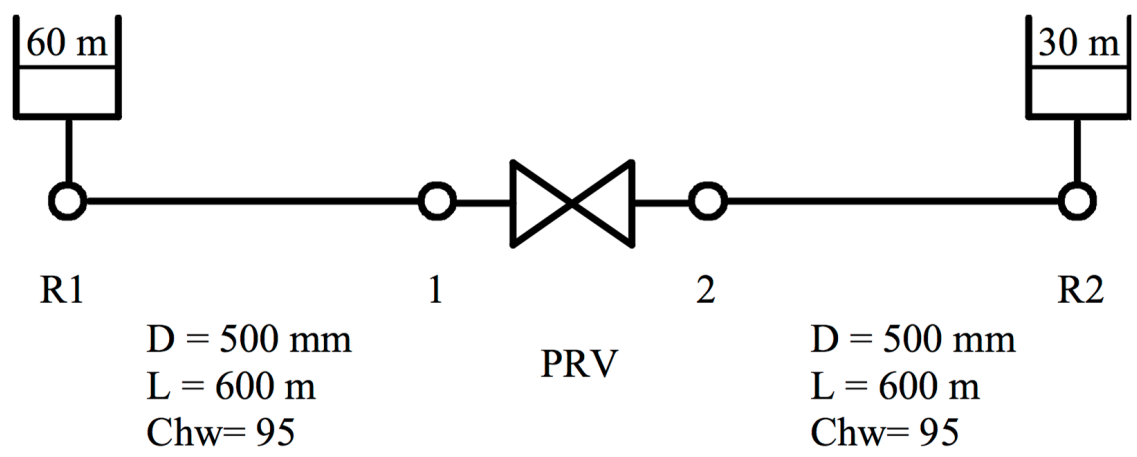

Figure 44. Network 1 with 1 PRV between two tanks.

406 The ground levels of nodes 1 and 2 are zero. Three target heads on node 2 were tested: Hset $=$

hydraulic grade line, b) device active (an equivalent local head loss is created with coefficient $\mathrm{K}^{*}=34.5$ ), c) valve closed, target too low to achieve due to presence of tank R2. The three

413 Situation a): the initial solution is $\mathrm{K}^{0}=0 . \mathrm{Next}, \mathrm{K}^{1}=-46$ does not satisfy the non-negativity constraint, therefore the damping parameter $\mathrm{e}_{1}$ in Eq. (12) is increased; the step size is reduced and, for $\mathrm{k}=4, \mathrm{~K}^{4}$ is close to zero and the algorithm stops; gradient in Eq. (9) is positive and has a value of $\nabla c(0)=2,547,090$; the Karush Kuhn and Tucker equations (10) and (11) are satisfied. 
Newton-Raphson method; $\mathrm{e}_{\mathrm{i}}$ tends rapidly towards zero; the gradient is cancelled out.

Situation c): the PRV is gradually closed to achieve the equivalent head loss of coefficient

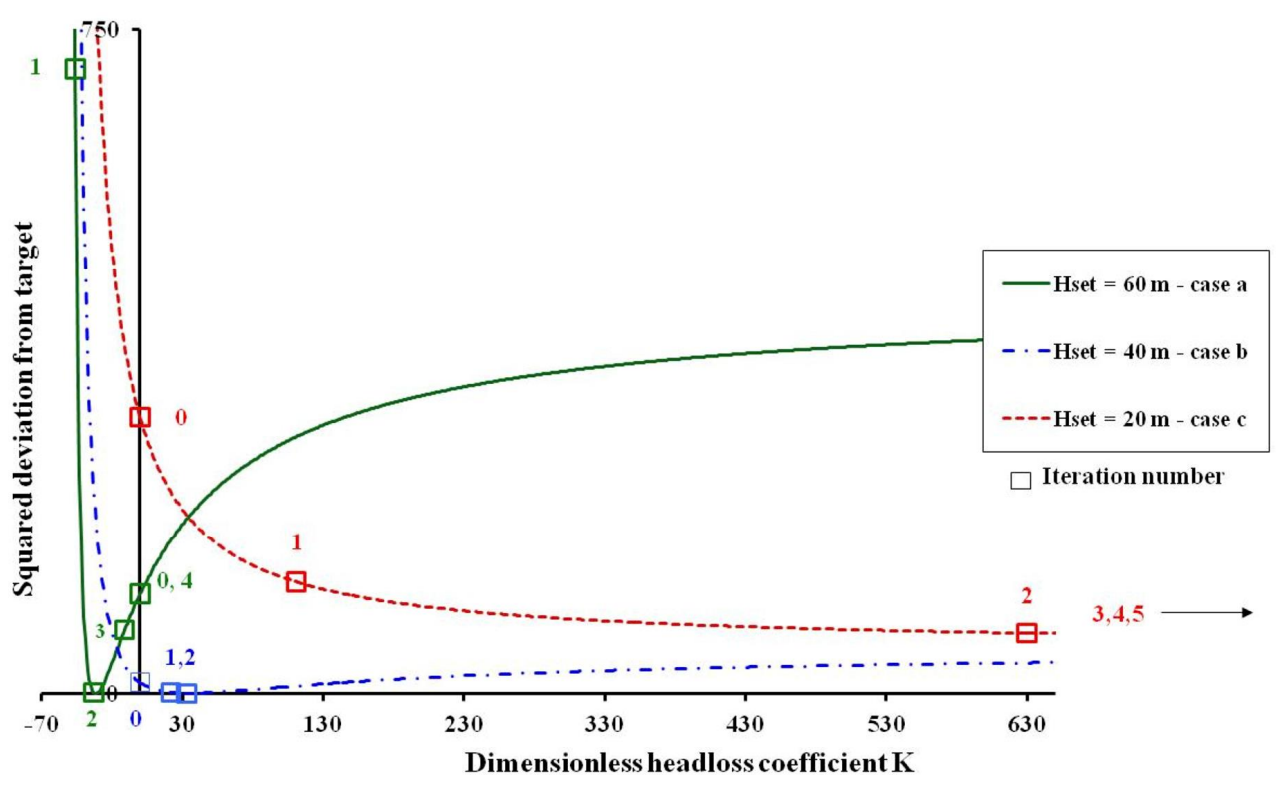

Figure 5.5. Algorithm performance at each iteration.

Mis en forme : Anglais (États Unis) Code de champ modifié Mis en forme : Anglais (États Unis) Mis en forme : Anglais (États Unis)

\section{A FCV and a PRV in series.}

The second example network shown in Figure 6Figure 6 was also proposed by Simpson (1999). This network consists of a flow control valve (FCV) and a pressure-reducing valve in series between two tanks. The tank T1 fills the tank T2 by gravity only. For non-valve configurations (or equivalently the two control valves both inactive and having no minor head losses), the flow rate and the piezometric head at the middle of the path would be 


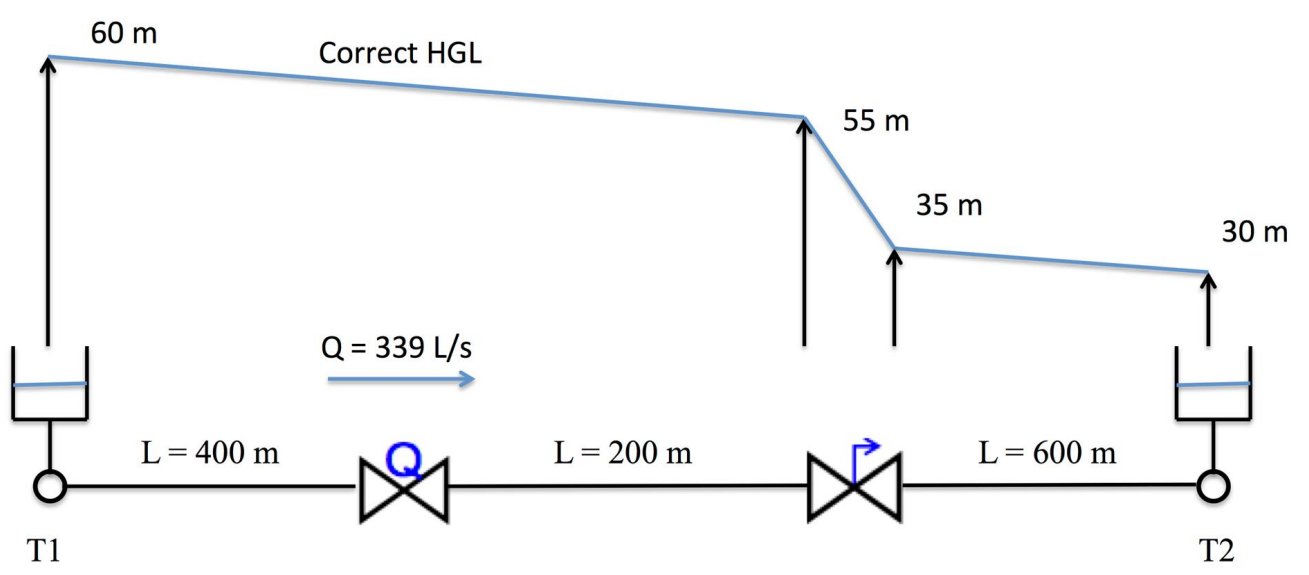

438 Figure 66. Network 2 with a FCV and a PRV in series between two tanks.

439 The main reason why previous versions of Epanet (e.g., version 2.00.10) may fail to converge or converge to an incorrect solution, for this simple configuration with control valves is that

the algorithm may fail to determine the correct statuses of the valves. In the proposed method, a continuous approach is used for both FCVs and PRDs. A flow control valve is modeled as a local headloss that penalizes all violation of the flow set point. With this approach a FCV and a PRV in series will pose no problem. The Table 1Table 1 summarizes the iterations of the Levenberg-Marquardt method for estimating the pressure valve settings.

With CV-Count is the number of pressure control valve components that has converged; RSS is the residual sum of squares i.e., $\mathrm{c}\left(\mathrm{K}_{\mathrm{i}}\right)$ with $\mathrm{m}=0$; GRAD/SD is the norm of the gradient along the search direction; LM factor $\mathrm{e}_{\mathrm{i}}$ is the Levenberg-Marquardt damping factor; and the last column give the dimensionless friction factor that creates the local headloss $0.5 \mathrm{~K}^{*} \mathrm{~V}^{2} / \mathrm{g}$. 
Table 11. Convergence for the network with one FCV and one PRV in series.

\begin{tabular}{|r|r|r|r|r|r|}
\hline Iteration \# & CV_Count & \multicolumn{1}{l|}{ RSS } & \multicolumn{1}{l|}{ GRAD/SD } & LM factor $\boldsymbol{e}_{\mathbf{i}}$ & \multicolumn{1}{c|}{ K PRV } \\
\hline 0 & 0 & 50.00000 & 1881507.19753004 & 0.00010 & 0.00000 \\
\hline 1 & 0 & 8.58045 & 269899.11571403 & 0.00004 & 40.19445 \\
\hline 2 & 0 & 0.89534 & 40111.55927071 & 0.00002 & 88.28532 \\
\hline 3 & 0 & 0.02955 & 4884.57232911 & 0.00000 & 122.05247 \\
\hline 4 & 0 & 0.00006 & 206.63313520 & 0.00000 & 131.20525 \\
\hline 5 & 0 & 0.00000 & 0.48852255 & 0.00000 & 131.67368 \\
\hline 6 & 0 & 0.00000 & 0.00000380 & 0.00000 & 131.67480 \\
\hline 7 & 1 & 0.00000 & 0.00000007 & 0.00000 & 131.67480 \\
\hline
\end{tabular}

455 The row iteration 0 corresponds to an initialization with $\mathrm{K}=0$, with the PRV assumed fully

456 open. The head at node 2 is $\mathrm{H}_{2}(\mathrm{~K}=0)=45 \mathrm{~m}$, which is $10 \mathrm{~m}$ above the set point. The RSS is

$45750 \mathrm{~m}^{2}$. The reductions of the RSS and of the Gradient are quadratic. The damping factor $\mathrm{e}_{\mathrm{i}}$

458 decreases by $60 \%$ at each iteration. Since there is no open or closed pressure control valve,

459 there is no need to solve the second-stage problem. Moreover, modeling flow control valves

460 with Eq. (4), penalizing the head loss if the flow setting is violated, requires no special

461 treatment for an open FVC. This is a clear advantage.

462

463

\section{A PSV and a PRV in series}

464

The third example network consists of two separate PSV and PRV in series as shown in

465 Figure 7Figure 7. Water flows from a reservoir to a Tank for a distance of $2 \mathrm{~km}$. Halfway

466 between the reservoir and tank are two separate devices in series configured to model a
Mis en forme : Anglais (États Unis)

Code de champ modifié

Mis en forme : Anglais (États Unis) 


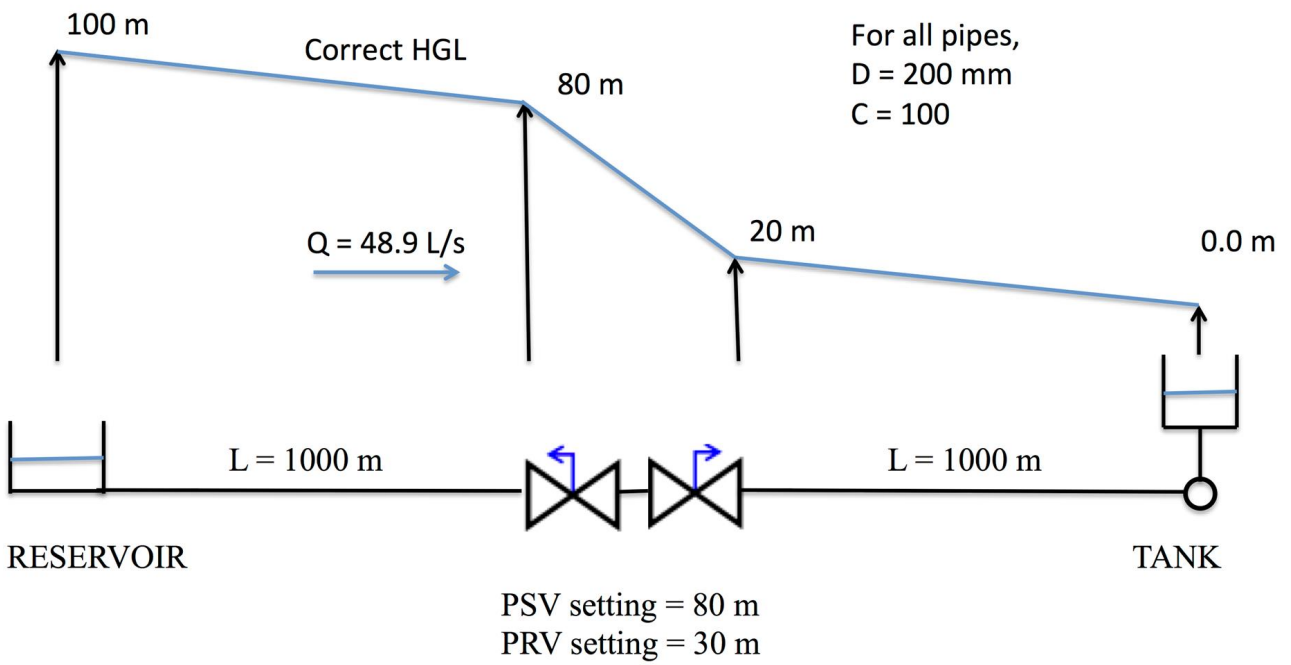

Figure 77. Network 3 with a PSV and a PRV in series between a reservoir and a tank.

At the end of the simulation run, the solution should be as shown in the Figure 7Figure 7. The PSV is active and yields a local headloss of $60 \mathrm{~m}$ with a dimensionless coefficient $\mathrm{K}^{*}=$

480 its setting. The flow rate is $48.9 \mathrm{~L} / \mathrm{s}$. 

explained with the fact that the 2 valves interact strongly with each other.

Table 22. Initial convergence for the network with one PSV and one PRV in series.

\begin{tabular}{|r|r|r|r|r|r|r|}
\hline $\begin{array}{c}\text { Iteration } \\
\#\end{array}$ & CV_Count & RSS & GRAD/SD & \multicolumn{1}{c|}{$\begin{array}{c}\text { LM } \\
\text { factor } \boldsymbol{e}_{\mathbf{i}}\end{array}$} & K PSV & K PRV \\
\hline 0 & 0 & 649.75005 & 227019.02185376 & 0.00010 & 0.00000 & 0.00000 \\
\hline 1 & 0 & 100.36013 & 33791.61183555 & 0.00004 & 75.35540 & 75.35540 \\
\hline 2 & 0 & 28.46590 & 4479.20812686 & 0.00002 & 136.42557 & 136.42557 \\
\hline 3 & 0 & 25.01620 & 265.86395946 & 0.00000 & 157.61510 & 157.61510 \\
\hline 4 & 0 & 25.00000 & 1.40547468 & 0.00000 & 159.28421 & 159.28421 \\
\hline 5 & 0 & 25.00000 & 0.00004447 & 0.00000 & 159.29323 & 159.29323 \\
\hline 6 & 2 & 25.00000 & 0.00000079 & 0.00000 & 159.29323 & 159.29323 \\
\hline
\end{tabular}

489

490 To move the solution away from the local minimum solution, the recommended method is to

penalize the least-squares criterion with a Tikhonov term (Eqs. 8 and $12, \mathrm{~m}>0$ and $\mathrm{r}_{0}=0$ for the PRV). In addition the following rule is applied: after convergence, if a situation with active or closed valve, but satisfied constraint occurs the valve with the highest residual is opened. This applies with combined PSV/PRV valves but also to other valve configurations with strong interaction.

The 6 first iterations are then followed by 6 further iterations with the PRV open as shown in Table 3Table 3. The algorithm converges to the correct valve status solution (active PSV and open PRV).

In addition, the solution at iteration 12 is equivalent to the solution at iteration 6: not only the criterion cost RSS $=25 \mathrm{~m}^{2}$ but also the hydraulic grade line with $75 \mathrm{~m}$ upstream the PSV, and 
$50325 \mathrm{~m}$ downstream the PRV. The head loss of the PSV is $50 \mathrm{~m}$ with a dimensionless

504 coefficient $\mathrm{K}=318.6$, which is equal to the sum of the head losses in iteration 6 . However,

505 the algorithm has to continue to the second stage to determine the correct setting of the PSV.

506 The RSS contribution for the PRV is removed from the total RSS as the valve is open. These

507 iterations are summarized in Table 4Table 4.

Table 33. Valve status solution for the network with one PSV and one PRV in series.

\begin{tabular}{|r|r|r|r|r|r|r|}
\hline $\begin{array}{c}\text { Iteration } \\
\#\end{array}$ & CV_Count & RSS & GRAD/SD & \multicolumn{1}{c|}{ LM } \\
factor $\boldsymbol{e}_{\mathbf{i}}$ & K PSV & K PRV \\
\hline 7 & 0 & 90.32851 & 30282.48742520 & 0.00010 & 159.29323 & 0.00000 \\
\hline 8 & 1 & 27.76165 & 3935.48041489 & 0.00004 & 277.43718 & 0.00000 \\
\hline 9 & 1 & 25.01060 & 214.55220639 & 0.00002 & 315.86958 & 0.00000 \\
\hline 10 & 1 & 25.00000 & 0.92318209 & 0.00000 & 318.57460 & 0.00000 \\
\hline 11 & 1 & 25.00000 & 0.00002352 & 0.00000 & 318.58644 & 0.00000 \\
\hline 12 & 2 & 25.00000 & 0.00002352 & 0.00000 & 318.58644 & 0.00000 \\
\hline
\end{tabular}

509

510 The exact setting of the PSV $\left(\mathrm{K}^{*}=486.5\right)$ is obtained after 6 additional iterations.

511 Table 44. Second-stage solving for the network with one PSV and one PRV in series.

\begin{tabular}{|r|r|r|r|r|r|}
\hline $\begin{array}{c}\text { Iteration } \\
\#\end{array}$ & CV_Count & RESID_SS & GRAD/SD & $\begin{array}{c}\text { LM } \\
\text { factor } \boldsymbol{e}_{\mathbf{i}}\end{array}$ & K PSV \\
\hline 13 & 1 & 12.50000 & 3652.53528151 & 0.00010 & 318.58644 \\
\hline 14 & 1 & 0.37937 & 434.37774607 & 0.00004 & 451.11238 \\
\hline 15 & 1 & 0.00068 & 16.82032793 & 0.00002 & 484.93499 \\
\hline 16 & 1 & 0.00000 & 0.03264390 & 0.00000 & 486.49091 \\
\hline 17 & 1 & 0.00000 & 0.00000033 & 0.00000 & 486.49396 \\
\hline 18 & 2 & 0.00000 & 0.00000033 & 0.00000 & 486.49396 \\
\hline
\end{tabular}

512

513 Figure 8Figure 8 shows the nodal heads for the 9 first hours. The tank is cylindrical with 20

$514 \mathrm{~m}$ for the maximum level and $10 \mathrm{~m}$ for the diameter. $\mathrm{J} 1$ is a junction node just upstream the

515 PSV and J3 another one just downstream the PRV. The tank level was updated every hour
Mis en forme: Anglais (États Unis)

Mis en forme : Anglais (États Unis)

Mis en forme: Anglais (États Unis)

Code de champ modifié

Mis en forme : Anglais (États Unis)

Mis en forme: Anglais (États Unis)

Mis en forme : Anglais (États Unis)

Code de champ modifié

Mis en forme : Anglais (États Unis)

Mis en forme : Anglais (États Unis) 
The 9-hour simulation requires a total of 112 iterations.

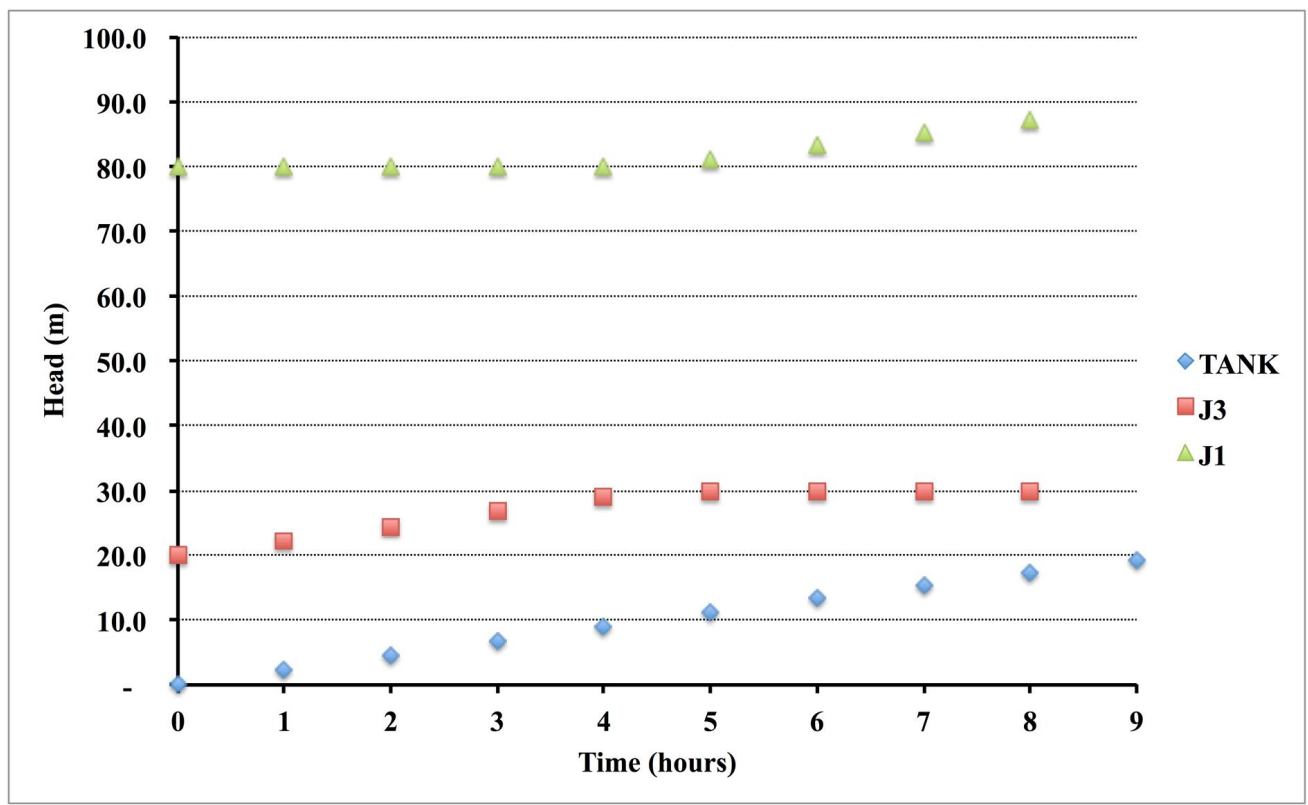

Figure 88. Head time series for selected nodes in network 3.

\section{Two PRVs in parallel.}

The fourth example network consists of two PRVs in parallel as shown in Figure 9Figure 9. Mis en forme : Anglais (États Unis)

The system uses a tank or a pumping station to supply consumers at node JCons. When the Mis en forme : Anglais (États Unis)

524 pumps are operating the tank is filling through a top inlet. When the pumps are switched off,

525 the tank supplies water to the system. The latter situation is represented in Figure 9Figure 9.

526 Water flows from the tank to node J1. Then, the flow separates in two different paths with a

527 PRV on each. The PRVs are situated $1 \mathrm{~km}$ upstream the node JCons. The pressure settings are $50 \mathrm{~m}$ for both PRVs. All node elevations are $200 \mathrm{~m}$. The level in the Tank is $3 \mathrm{~m}$ above its bottom level of $292 \mathrm{~m}$. The lengths of all three pipes are 1,000 $\mathrm{m}$ and their Hazen-Williams coefficients are 95. The demand at JCons is $8.5 \mathrm{~L} / \mathrm{s}$. 
Tank

$\mathrm{D}=250 \mathrm{~mm}$

Figure 29: Network 4 with two PRVs in parallel.

The Table 5 Table 5 summarizes the iterations of the Levenberg-Marquardt method. It converges in 12 iterations to a global optimum (RSS $=0$.). It may be seen that at iterations 2 and 3 the damping factor $e_{i}$ has been multiplied by ten. This was done to correct the search

Mis en forme : Anglais (États Unis)
Mis en forme : Anglais (États Unis)
Code de champ modifié
Mis en forme : Anglais (États Unis)
Mis en forme: Anglais (États Unis)
Mis en forme: Anglais (États Unis)
direction in order to have an effective descent for the RSS criterion. The two valves are operating and produce a local head loss of $44.71 \mathrm{~m}$ for PRV1, and $44.47 \mathrm{~m}$ for PRV2. The difference $0.24 \mathrm{~m}$ corresponds to the linear head loss of the $1 \mathrm{~km}$ long pipe J1/JPumping. A flow rate of $4.25 \mathrm{~L} / \mathrm{s}$ flows through this pipe. The dimensionless coefficients are relatively large: $\mathrm{K}_{\mathrm{PRV} 1}=15,164$ and $\mathrm{K}_{\mathrm{PRV} 2}^{*}=15,083$. These two valves are strongly linked, which plays a role for the weaker, linear convergence rate. 
Table 55. Convergence for the network with two PRVs in parallel.

\begin{tabular}{|r|r|r|r|r|r|r|}
\hline $\begin{array}{c}\text { Iteration } \\
\#\end{array}$ & CV_Count & RSS & GRAD/SD & \multicolumn{1}{c|}{ LM } \\
factor $\boldsymbol{e}_{\mathbf{i}}$ & \multicolumn{1}{|c|}{ K PRV1 } & \multicolumn{1}{|c|}{ K PRV2 } \\
\hline 0 & 0 & 1988.96816 & 1185.48303586 & 0.00010 & 0.00000 & 0.00000 \\
\hline 1 & 0 & 0.01086 & 0.26839385 & 0.00004 & 13517.19639 & 17036.82993 \\
\hline 2 & 0 & 0.17871 & 0.26839385 & 0.00040 & 13517.19639 & 17036.82993 \\
\hline 3 & 0 & 0.04189 & 0.26839385 & 0.00400 & 13517.19639 & 17036.82993 \\
\hline 4 & 0 & 0.00772 & 0.32911957 & 0.00160 & 13763.48414 & 16695.22089 \\
\hline 5 & 0 & 0.00463 & 0.89014765 & 0.00064 & 14189.38031 & 16134.05340 \\
\hline$\downarrow$ & & & & & & \\
\hline 12 & & 0.00000 & 0.00000000 & 0.00000 & 15164.07956 & 15083.08428 \\
\hline
\end{tabular}

547

548 The residual Jacobian matrix $\mathbf{J}$ at iteration 10 is as follows:

549

$$
\mathbf{J}=\left(\begin{array}{ll}
163.1268 & 163.0637 \\
163.0637 & 163.2535
\end{array}\right)
$$

550 It may be seen than the 2 PRVs influence each other to the same extent and when one of

551 PRVs experiences a small change, a similar change is expected in the other valve.

552

\section{3}

554

559 function when the flow setting is violated. Check valves are modeled as special flow control
In this method, flow control valves are handled by imposing a penalty on the valveô headloss

\section{CONCLUSION}

A new method is presented for handling control valves (including check valves) in hydraulic network modeling. In this method, the behavior of check and control valves are described by continuous functions rather than the mixed discrete-continuous formulation commonly used. valves with a minimum flow rate setting of zero. The modified headloss functions for flow control valves are incorporated into the hydraulic network equations and the resulting 
Pressure control valves (such as pressure reducing and pressure sustaining valves) are handled externally to the hydraulic solver through an optimization routine. The goal of the optimization is to find the secondary loss coefficients of the pressure control valves that will minimize the differences between the nodal and the target pressures.

The proposed method has several benefits compared to the current discrete-continuous formulation. The derivatives of the heads in relation to the input parameters can be written explicitly as functions of the flow rates, and the gradients of the functions with respect to the optimization variables can be obtained analytically. This, in conjunction with the fact that only linear constraints are required in the optimization process, provides good conditions for fast convergence of the method. The robustness of the optimization is ensured by using a Levenberg-Marquardt projection minimization algorithm, for which global convergence is guaranteed.

It is shown with several case studies than the method finds interesting solutions to control valve problems without resorting to ómodeling tricksô It is proved to be efficient on problematic case studies.

While only control valves were considered in this paper, variable speed pumps and handling of high-lying nodes with negative pressures (Piller and Van Zyl 2009) can also be included in the proposed algorithm. 


\section{REFERENCES}

Bazaraa, M. S., Sherali, H. D., and Shetty, C. M. (1993). « Nonlinear Programming - Theory and Algorithms. », Wiley, 638 p, second edition.

Carpentier, P., Cohen, G., and Hamam, Y. (1985). "Water Network Equilibrium, Variational Formulation and Comparison of Numerical Algorithms." EURO VII, Bologna, IT.

Chandrashekar, M., and Stewart, K. H. (1975). "Sparsity Oriented Analysis of Large Pipe Networks." Journal of the Hydraulics Division, 101(HY4), 341-355.

Collins, M., Cooper, L., Helgason, R., Kennington, R., and Leblanc, L. (1978). "Solving the Pipe Network Analysis Problem using Optimization Techniques." Management Science, 24(7), 747-760.

Cross, H. (1936). "Analysis of Flow in Networks of Conduits or Conductors." Bulletin No. 286, University of Illinois Engineering Experimental Station.

Deuerlein, J., Cembrowicz, R. G., and Dempe, S. (2005). "Hydraulic Simulation of Water Supply Networks Under Control." World Water and Environmental Resources Congress (EWRI05), Anchorage (AK), US, printed by ASCE.

Deuerlein, J., Simpson, A., R., and Gross, E. (2008). "The Never Ending Story of Modeling Control-Devices in Hydraulic Systems Analysis." 10th International Water Distribution System Analysis conference (WDSA), 17-20 August 2008, Kruger National Park, ZAF, printed by ASCE, Volume 340/, 72.

Deuerlein, J., W., Simpson, A., R. , and Dempe, S. (2009). "Modeling the Behavior of Flow Regulating Devices in Water Distribution Systems Using Constrained Nonlinear Programming." Journal of Hydraulic Engineering, 135(11), 970-982.

Epp, R., and Fowler, A. G. (1970). "Efficient Code for Steady-State Flows in Networks." Journal of the Hydraulics Division, 96(HY1), 43-56. 

129.

Ortega J.M. and Rheinboldt W.C. (1970). ñIterative solution of nonlinear equations in several variables.ò, Computer Science and Applied Mathematics, Academic Press, 1970. 21 July 2014).

Piller, O. (1995). "Modeling the behavior of a network - Hydraulic analysis and sampling procedures for parameter estimation." PhD thesis in Applied Mathematics from the Mathematics and Computer Science Doctoral School at the University of Bordeaux (PRES), defended on 03 February 1995, 288 pages, Talence, France.

Piller, O., and Brémond, B. (2001). "Modeling of Pressure Regulating Devices: A Problem now Solved." World Water \& Environmental Resources congress, EWRI01, Orlando (FL), US, printed by ASCE.

Piller, O., Gancel, G., and Propato, M. (2005). "Slow Transient Pressure Regulation in Water Distribution Systems." Eight International Conference on Computing and Control in the Water Industry CCWI05 OWater Management for the 21st Centuryô University of Exeter, UK, printed by Centre for Water Systems, Volume 1/2, 263-268.

Piller, O., and van Zyl, J. E. (2009). "Pressure-Driven Analysis of Network Sections Supplied Via high-lying Nodes." Computing and Control in the Water Industry 2009 'Integrating Water Systems', The Edge, University of Sheffield, printed by CRC press/Balkema, Volume 1/1, 257-262. 
637 Rossman, L. A. (2000). "EPANET User's manual." U.S. Environmental agency, Cincinnati, Ohio.

639 Simpson, A. (1999). "Modeling of Pressure Regulating Devices: The last major Problem to be Solved in hydraulic Simulation." Water Resources Planning and Management Conference, Tempe (AZ), US, printed by ASCE, 9p.

642 Todini, E., and Pilati, S. (1988). "A Gradient Projection Algorithm for the Analysis of Pipe Networks." Computer Applications for Water Supply and Distribution, Leicester Polytechnic, printed by Research Study Press Ltd., Volume 1/1.

645 Wood, D. J., and Charles, C. O. A. (1972). "Hydraulic Network Analysis Using Linear Theory." Journal of the Hydraulics Division, 98(HY7), 1157-1170. 


\section{LIST OF FIGURE CAPTIONS}

649 Figure 1. Headloss modeling of a flow control valve by external penalty. 11

650 Figure 2. Headloss modeling of a check valve by external penalty. 12

651 Figure 3. General form of criterion $c(K)$ to be minimized with $m$ taken at zero.

652 Figure 4. Network 1 with 1 PRV between two tanks. 20

\section{LIST OF TABLE CAPTIONS}

662 Table 3. Valve status solution for the network with one PSV and one PRV in series. 26

663 Table 4. Second-stage solving for the network with one PSV and one PRV in series. 26 